\title{
0 Estilo Como Negócio. A Tendência Retrô Utilizada Como Recurso Estratégico Nas Práticas da Gestão do Design
}

\author{
How Business Style. Trend Retro Used as Strategic Resour- \\ ce Management Practices in Design \\ por Caroline Basso, Richard Perassi Luiz de Souza \\ e Sharlene Melanie Martins de Araújo
}

RESUMO

Este artigo pretende analisar uma tendência no cenário atual da sociedade de consumo moderna. Reconhecer no contexto da cultura material o uso do estilo retrô como instrumento estratégico na prática da gestão do design. Apresenta-se a utilização do conceito de retrô inserido no design com apelo a formas estéticas específicas de determinadas épocas passadas, a caracterização do antigo, o uso de características clássicas marcantes utilizadas na gestão de negócios e na valorização da identidade de marcas e empresas. Empresas adotam toda a conceituação de design retrô como mecanismo estratégico da gestão do design diante do mercado de produtos e serviços. 0 tema revela no planejamento da gestão do design o uso da tradição e do passado como foco temático de aspectos de conteúdo. Além disso, pontua aspectos motivacionais das empresas na aplicação das estratégia de resgate das memórias materiais e culturais dos consumidores como parte do direcionamento estratégico.

Palavras Chave: Design Retrô. Cultura. Design Estratégico.

\section{ABSTRACT}

This article aims to analyze a trend in the current scenario of the modern consumer society. Recognizing the context of material culture using retro style a strategic tool in the practice of management design. Shows the use of the concept of retro inserted into the design with aesthetic appeal to specific forms of certain ages past, the characterization of the former, the use of classical features outstanding used in management business and development of identity of brands and companies. Companies adopt the whole concept of retro design as a mechanism of strategic management design on the market of products and services. The theme reveals the planning of management design the use of tradition and the past focused on thematic aspects of content. In addition, this motivational aspects of the companies in implementing the strategy of rescue materials and cultural memories of consumers as part of the strategic direction.

Keywords: Retro Design. Culture. Strategic Design. 


\section{Introdução}

\subsection{A cultura material contemporânea}

A cultura descreve o caráter significativo da vida da coletividade e também pode ser visualizada como uma esfera mais refinada de objetos culturais valorizados, bem como de valores ligados a esses objetos. Os objetos representam e traduzem formalmente a cultura e o mercado se utiliza dessa representação no desenvolvimento de produtos e fomentam o consumo. Segundo Melo (2008, p. 28) "através dos produtos os seres humanos são definidos como grupos sociais, se comunicam e marcam sua forma de existência."

Na cultura material contemporânea a capacidade inerente de criar uma diversidade de atuais esquemas de consumo, vem concebendo novas dinâmicas no mercado. Novas configurações emergem dos diversos processos sociais e culturais do nosso meio atual e modificam a maneira como lidamos e nos relacionamos com os objetos, produtos e serviços disponíveis. 0 meio social interagindo com esses produtos, definindo escolhas, propagando comportamentos revelam novas orientações nas relações de consumo e na cultura material.

0 termo cultura material está relacionado com a finalidade ou sentido que os objetos têm para um povo numa cultura, ou seja, a importância e influência que exercem na definição da identidade cultural de uma sociedade. 0 que é material, físico, objeto ou artefato é entendido pelos seres humanos como um legado, algo para ser apreendido, usado e preservado, que ensina a reproduzir o mesmo objeto ou guardar a sua memória.

0 ambiente cultural no qual estamos inseridos sempre foi motivador de novos direcionamentos no mercado e no desenvolvimento de produtos. Além do caráter inicial das funções práticas e estéticas os objetos possuem um simbolismo significativo nesse contexto. Scolari (2008, Apud Lobach, 2001 pg.12) explica que “A função simbólica dos objetos diz respeito aos aspectos espirituais, psíquicos e sociais do uso. Deriva dos aspectos estéticos do produto, que servem como referências para associações com experiências passadas e para associações de ideias com outros âmbitos da vida. Nesse sentido revela-se a concepção inicial desta explanação. A simbologia dos objetos, dos produtos que fazem parte do nosso cotidiano são parte do eixo central da análise sobre as novas propostas sobre o mercado de consumo, produtos e design. De acordo com Burdek (2010, pg. 322) símbolo "de forma geral significa um sinal que por meio de uma combinação (convenção) possui significado cultural".

Adicionando valores emocionais na concepção e no aperfeiçoamento dos produtos, funções como a estética se estendem e acabam inovando. Para Mozota (2011, pg.119) "a estética é entendida como emoção compartilhada. Um produto torna-se um "objeto cult". A estética transforma um novo produto em uma inovação social, que é o processo pelo qual uma nova significação é introduzida no sistema social."

Nota-se na atual conjuntura da sociedade que as recentes relações com os produtos, e os significativos valores simbólicos atribuídos a eles, são fatores significativos nas 


\section{Estilo Como Negócio. A Tendência Retrô Utilizada Como Recurso Estratégico Nas Práticas da Gestão do Design}

investigações dos padrões da sociedade. Quando um objeto não mais é especificado por sua função, é qualificado por suas "características". Os objetos então tornam-se sistemas para verificar práticas sociais. (MOZOTA 2010 Apud Barthes,1970 pg. 116).

\subsection{A produção material moderna e o estilo retrô}

Nas relações familiares, no trabalho, com o grupo de amigos e outras mais que integram a sociedade são criados gêneros de afinidades que se traduzem em novas identidades e consequentemente em novas linhas de consumidores e alternativas estratégicas de negócios pelas empresas. Mergulhados em uma diversidade de produtos e serviços disponíveis no mercado, esses grupos de consumo se consolidam adquirindo hábitos específicos. Essa situação atual do mercado visivelmente sobrecarregado na produção e propagação de ideias sobre novos produtos tem intensificado uma demanda por inovação e diferenciação. Esse ambiente da produtividade material tem gerado fenômenos particulares nos costumes dos consumidores e isso tem sido um foco produtivo muito atraente para as empresas. Constata-se um clima propício de investimentos pelas empresas e uma busca dos consumidores por atrativos em produtos que cada vez mais tenham um papel expressivo na construção do estilo de vida.

A cultura material incorporada à multiplicação de objetos, de serviços e bens materiais trouxe uma condição de consumo onde o novo é superior ao antigo, precipitando a inutilização e o descarte dos produtos. E essa realidade vem estabelecendo um cenário antagônico dentro dessa conjuntura. Um fenômeno onde o excesso de modernidade dos produtos trouxe o apelo aos aspectos do passado. Isso vem ocasionando a manifestação prática de uma expressão que vem sendo utilizada conceitualmente no design: 0 estilo retrô. Esse conceito vem sendo amplamente utilizado tanto de maneira prática na criação e desenvolvimento de produtos e vinculado ao design. De maneira introdutória consideram-se produtos, serviços e produtos de comunicação de diversas categorias do mercado criados ou produzidos nos dias atuais com atributos e aspectos estéticos de outras épocas.

Para Oliveira (2010, Apud Faggiani 2006 pg.7) esta busca pelo retrô nada mais é que a atualização e/ou modernização de um estilo, substituindo seus componentes por outros mais recentes e eficazes. 0 autor conceitua ainda o retrô como sendo algo inspirado nas características formais do estilo do passado, mas com processos de fabricação atuais, indicando nos objetos características do passado. A conceituação sobre o assunto abre discussões sobre expressões agregadas e amplia o conteúdo sobre o tema. Rohenkohl (2011 pg.151) trata da distinção em torno dos termos:

1. Antiguidade: É o objeto próprio do passado, contido de valor histórico;

2. Réplica: É o objeto produzido hoje, imitando fielmente um objeto específico particular do passado ou não;

3. Vintage: É o objeto que foi do passado incorporado no repertório atual. É um fato muito presente do segmento de moda;

4. Retrô: É o objeto produzido hoje, inspirado nas características formais do estilo do 
passado, com processos de fabricação atuais. De modo geral indica em uma peça algumas características do passado, ou seja, envolve uma reciclagem de estilos.

A autora acrescenta ainda que o conceito retrô "é uma combinação entre o clássico e o moderno, em que o redesenho de um produto é abordado a partir de temas do passado de forma criativa e lançados ao mercado atual com um novo caráter, portanto, "moderno".

Explorando a sociedade de consumo atual e suas propriedades verifica-se a tentativa de atenuar os excessos da modernidade. A instalação da nostalgia na cultura de mercado assim como a predileção a formas e temáticas já consagradas no passado é a demonstra o impulso em estabelecer uma conexão com objetos de conteúdo informativo e comunicativo ligado às memórias coletivas. Um objeto favorito é um símbolo que induz a uma postura mental positiva, um lembrete que nos traz boas recordações ou, por vezes, uma expressão de nós mesmos. E esse objeto sempre tem uma história, uma lembrança e algo que nos liga pessoalmente àquele objeto em particular, àquela coisa em particular. (NORMAN, 2008, pág.26). Esse aspecto emocional tem sido um critério de apoio no uso da nostalgia e um argumento atrativo para investimentos nesse gênero. 0 resgate da forma, estilo e manifestações de outras épocas do passado atuantes tem servindo de base para a concepção de produtos modernos e tecnológicos tem sido cada vez mais observado no mercado de produção material contemporânea.

Não é possível definir o ano em que a estilo começou a se sobressair, mas a busca por nostalgia é uma característica do século 21. A cultura material farta de acontecimentos e produção despertou uma "nostalgia mercadológica". A situação social transparece esse momento. A cada novo elemento de inovação que é ultrapassado estabelece-se uma certa condição de desamparo nos consumidores. Esse evento rapidamente é preenchido com novos produtos. Esse ritmo acelerado fomentou essa condição no mercado. Essa atmosfera presente que evidencia essa invocação do passado, com características visuais e conceituais reflete o momento cultural que vivemos hoje. Há uma busca por identidade, um foco na interpretação de tudo que já foi criado na trajetória cultural e também uma constante busca por inovação e estímulos à tecnologia. Essas circunstâncias oferecem margem para a aplicação do uso referencial do retrô, do estilo antigo e de suas variações como mecanismo estratégico na hora de conceber novos produtos, nos planos de comunicação, em projetos de inovação e renovação de uma empresa. De acordo com Mozota (2011, pg.188) "Os elos entre o design, identidade e cultura devem ser encontrados nos símbolos visuais (gráficos e espaciais), mas também no clima psicológico que é desenvolvido pelo modo como esses símbolos são percebidos".

\subsection{0 design retrô como estratégia na gestão do design}

É muito evidente o papel significativo que o design vem desempenhando junto às organizações. A international Counciel Societies of Industrial Design (ICSID) na descrição de Mozota (2011 pg. 16) oferece uma definição acerca do conceito e objetivo do design: 


\section{Estilo Como Negócio. A Tendência Retrô Utilizada Como Recurso Estratégico Nas Práticas da Gestão do Design}

0 design é uma atividade criativa cujo objetivo é estabelecer as qualidades multifacetadas de objetos, processos, serviços e seus sistemas em ciclos de vida completos. Portanto, design é o fator central da humanização inovadora de tecnologias e o fator crucial do intercâmbio cultural e econômico.

$\mathrm{Na}$ prática do mercado o design se insere numa empresa desde a fase inicial do plano criativo até o cumprimento dos processos seguintes. Por desempenhar esses papéis acaba incorporando virtudes estratégicas na atribuição de valores aos produtos e serviços, diferenciando-os da concorrência e aumentando a sua competitividade no mercado. Nesse quadro o design está claramente relacionado ao processo de gestão das organizações.

A gestão do design é a implementação do design como um programa formal de atividades dentro de uma corporação por meio da comunicação da relevância do design para suas metas corporativas de longo prazo e da coordenação de recursos de design em todos os níveis da atividade corporativa para atingir seus objetivos. (MOZOTA 2001 pg.95)

0 ambiente cultural e os reflexos perceptivos que esse ambiente disponibiliza, estimula profissionais do design a utilizar os benefícios da gestão nos processos estratégicos de uma empresa. Beneficiar-se de uma atmosfera específica que se manifesta no mercado pode servir como base para mudanças e ações. Explorar essa predisposição do mercado acompanhando os comportamentos sociais abre possibilidades na criação de novos conceitos e novos métodos de gerenciamento que estejam conectados com as necessidades dos consumidores.

A tendência que mistura elementos contemporâneos com pequenas menções de características do passado foi agilmente identificada por empresas e por profissionais que investem no design sutilmente saudosista e recriam produtos que viraram ícones em alguma época. Segundo Hernandez (2011 pg. 12) 0 termo "tendência" que especifica essa nova orientação do mercado caracteriza-se como "uma propensão ou força que indica uma direção, um movimento em sentido determinado." A percepção dessa inclinação nostálgica se traduz em projetos de comunicação, desenvolvimento de produtos e como argumento para novas propostas de gestão do design como a valorização de produtos por meio da diferenciação do mercado, foco na inovação, resgate da usabilidade entre outros. Todos esses elementos estão inseridos nos espaços conceituais presentes nos planos de gestão do design nas empresas que vem utilizando aspectos do design retrô.

Objetiva-se com este artigo reconhecer a aplicação do design retrô como estratégia na gestão do design. Identificar alguns conceitos de gestão inseridos em negócios que se utilizam dos conceitos de design retrô como ferramenta de inovação, diferenciação e valorização de produtos e serviços. Essa abordagem aponta recursos estratégicos reconhecidos nos conceitos de gestão que complementam os planos de negócios com 0 caráter retrô. Delimita-se a temática principal às questões indicadoras dessa prática na cultura material atual, aos conceitos básicos ligados ao tema e às motivações relacionadas ao uso dessa tendência pelas empresas no mercado.

Este artigo se caracteriza predominantemente como uma pesquisa teórica descritiva. Foram pesquisadas fontes teóricas de estudos relativamente recentes sobre 0 assunto por se tratar de uma temática fundamentalmente contemporânea. Artigos científicos 


\section{Estilo Como Negócio. A Tendência Retrô Utilizada Como Recurso Estratégico Nas Práticas da Gestão do Design}

publicados na última década juntamente com algumas fontes bibliográficas de autores fundamentais e modernos dos princípios da gestão do Design.

\section{Fundamentação Teórica}

No âmbito da instabilidade do mercado delineia-se uma infinidade de estímulos ao consumo, um fluxo intenso de informação sobre novos produtos, tecnologias e em consequência gera uma demanda exagerada à renovação e descarte desses artefatos. Esse ambiente multifacetado é o campo propício para um esboço sobre a percepção das manifestações modernas dos desejos e aspirações do consumidor. Mostra-se perceptível a necessidade atual dos usuários diante dessa imensidão de produtos e serviços uma demanda por estabilidade e segurança. Uma vontade resultante desse padrão moderno de consumo acelerado e que vem concebendo uma promoção ao chamado design retrô. Tudo que se apresenta direta ou indiretamente conectado a esse estilo, todas as vinculações ao passado, comercialmente possíveis, ganha destaque e promove novas sugestões de negócios para marcas e empresas. A estratégia de recordar hábitos, formas e a essência do que já passou traduz a aposta na "simplificação" do consumo. Diante disso elabora-se uma estrutura comunicativa visando à minimização do objeto propriamente, concentrando-se principalmente nas suas associações. 0 alicerce básico desse princípio é o estilo retrô utilizado como suporte para os fundamentos do design nos negócios. Fiell (2005 pg. 7) ressaltam o tema:

Enquanto o estilo é frequentemente um elemento complementar de uma solução de design, o design e estilo são duas disciplinas completamente distintas. 0 estilo está ligado à aparência e tratamento da superfície- às qualidades expressivas de um produto. 0 design por outro lado, está primeiramente ligado à resolução de problemas - tende a ser global na sua amplitude e geralmente procura simplificação e essência.

Numa fase em que o mercado vem considerando a valorização dos aspectos subjetivos ligados aos produtos, enriquecendo os significados e os sentidos relacionados, esses atributos tornam-se muitas vezes o diferencial deste produto. Para Mozota (2011 pg. 180) “a estratégia competitiva tem a ver com ser diferente. Significa escolher deliberadamente um conjunto diverso de atividades para oferecer uma combinação única de valor." Em um cenário em que as marcas necessitam ampliar o contato e estabelecer identificação com os consumidores diante da diversificação das funcionalidades dos produtos; o resgate dos valores tradicionais e da memória de uma marca se convertem em um ponto de diferenciação. As empresas tem investido no status antigo do apelo retrô por uma aposta de diferenciação de mercado. Mozota (2011, pg.239) expõe um novo contexto na segmentação:

Em relação a um critério de segmentação, mudanças recentes nas necessidades dos consumidores questionam a validade da segmentação tradicional em termos de estilo de vida, idade e categorias sociológica e profissional e sugerem um desenvolvimento da segmentação por nicho e até mesmo, a noção estética como um critério de segmentação. 


\section{Estilo Como Negócio. A Tendência Retrô Utilizada Como Recurso Estratégico Nas Práticas da Gestão do Design}

0 foco temático do design retrô não vem se expressando apenas como tendência, mas como elemento atuante na segmentação do comportamento do consumidor. Esse aspecto demonstra a exigência de se possuir no mercado uma maior fragmentação e a necessidade de mais ofertas de produtos e serviços. Nessa situação o mercado determina o sentido do desenvolvimento de projetos de comunicação, criação e venda de produtos se apoiando nos planos fundamentados pelo design estratégico. A concepção da gestão de negócios de uma empresa nesse tipo de projeto tem como propósito o investimento em reconhecer e consolidar a identidade da marca, utilizando a trajetória, seus valores iniciais e sua tradição. Essa condição é um incentivo criativo e inovador atribuído aos empresários e designers inseridos nesse quadro. Para Burdek (2010, pg. 363):

É exigida dos designers uma competência equivalente entre o projeto e economia, além de competência relativa ao contexto, tanto no que se refere a cultura da empresa como dos grupo-alvos de consumidores. 0 papel especial do design nessa conexão é o de visualizar os respectivos conceitos e ilustrar as estratégias de produtos, produzir "imagens" que se comuniquem de forma não verbal.

A contribuição desse perfil de negócios preliminarmente é a valorização da história da empresa bem como a da sociedade. A marca Granado de perfumaria e produtos de higiene é um dos exemplos de empresa que usam a tradição como fator de diferenciação. Fundada em 1870 pelo português José Antônio Coxito Granado no Rio de Janeiro, é considerada a botica mais antiga do Brasil. A chamada "pharmácia" manipulava produtos com extratos vegetais e plantas brasileiras além de importar produtos europeus para suas fórmulas. Foi destaque na época e conquistou a preferência dos oficiais da corte, inclusive com Dom Pedro II que no ano de 1880 conferiu à Granado o título de Farmácia oficial da Família Real Brasileira. Mais de um século depois a marca é destaque no mercado utilizando toda sua comunicação, design de embalagens e estratégias de venda com o apelo ao design retrô. A logo da marca foi modificada ao longo dos anos, mas nunca perdeu as características antigas. Na última década a marca tem investido muito em propaganda e evidenciado suas características de formato retrô como diferencial de consumo dos seus produtos. Investimento na conquista de novos consumidores idealizando o passado e toda sua presença estética agregada. A empresa acreditou nesse caminho nos negócios e comprou a marca Phebo, também tradicional no país nesse setor, e direcionou a comunicação no mesmo sentido. 0 destaque da empresa nos últimos tempos foi o lançamento de lojas exclusivas da marca em algumas cidades do país. Lojas com aspecto de farmácia antiga comercializam todos os produtos da marca e disponibilizam espaço exclusivo para produtos Phebo. Outra estratégia da sua gestão foi utilizada: toda a perspectiva do design retrô incorporado a conceitos modernos e atuais. Na tentativa de ligar seu nome ao mundo da moda e atrair um consumidor mais jovem, a Phebo fez parcerias com estilistas como Isabela Capeto e Amir Slama, que emprestam seus nomes a alguns produtos da marca. 


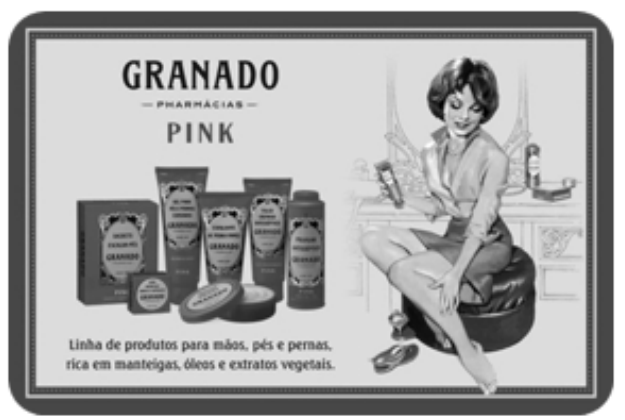

Figura 1 - Anúncio da Linha de produtos de beleza Granado. Fonte: www.estudiohibrido.com.br/portfoliocasa-granado-linha-pink

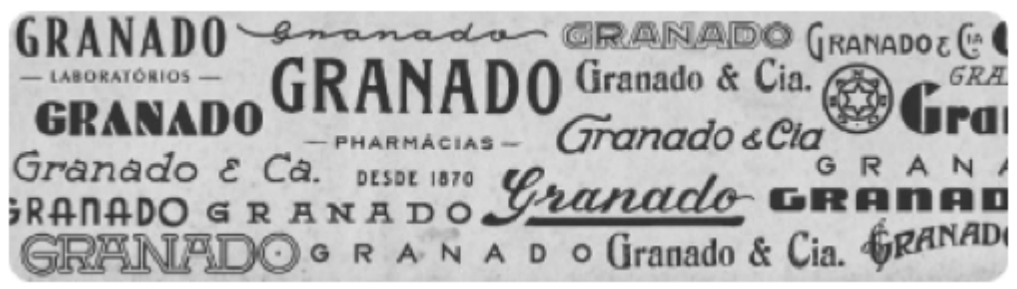

Figura 2 - As variações do estilo da fonte utilizada na logo marca. Fonte: www.retrospecto.com.br/estilogranado-pharmarcias-cosmeticos-vintage2

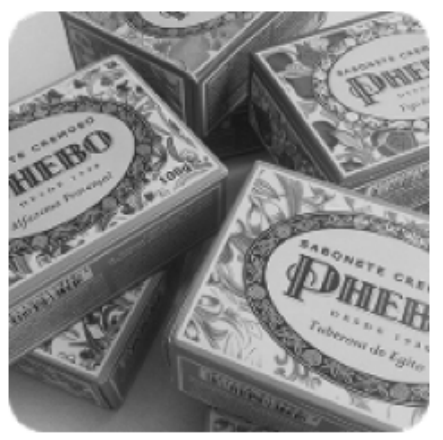

Figura 3 - Detalhe do design das embalagens. Fonte: www.athoshomem.com.brblogarchives

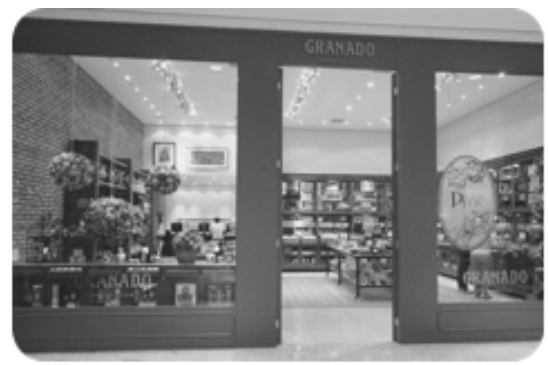

Figura 4 - Fachada da loja Granado no Rio de Janeiro. Fonte: www.retrospecto.com.br/estilogranado-pharmarcias-cosmeticos-vintage 


\section{Estilo Como Negócio. A Tendência Retrô Utilizada Como Recurso Estratégico Nas Práticas da Gestão do Design}

A valorização do passado histórico de uma empresa é uma tática de negócio que faz parte de muitos planos de comunicação, de estratégias usuais e superficialmente parece apenas um complemento no âmbito da gestão. Se isso fosse usado apenas como mais um recurso habitual e não como dominante nas estratégias de design de marcas de produtos não estaria tão visível no como uma tendência considerável no mercado atual. A memória dos consumidores, a reutilização de formas e conceitos tradicionais e marcantes até então ultrapassados agora servem como meios de interação da empresa e sociedade. Esse diálogo cheio de referências e elos comunicativos entre ambos vem se mostrando cada vez mais relevante e a o gerenciamento da comunicação dos produtos se utiliza desse contexto como uma alternativa. É necessário que o design gere e formule pontos de identificação que sejam afetivos em diversos níveis. Os produtos por si só atuam nesse processo como veículos de interação social, eles fornecem "possibilidades de integração" e formas diversas. (BURDEK 2010, pg. 239).

0 uso de padrões da cultura material é um dos eixos centrais nas novas estratégias das empresas. Empresas com anos de fundação, com passado histórico expressivo se utilizam da memória coletiva no relançamento de produtos. Utilizar referenciais do passado promove a construção de novas experiências com os consumidores. 0 grande número de marcas que vem utilizando a estratégia de relançar produtos já fora do mercado há muitos anos com as mesmas características visuais, conceituais da época constroem um novo sentido nessa interação. Novos consumidores são cativados mesmo se utilizando de situações e apelos às épocas que os usuários não tenham vivido na prática. A memória comum ajuda a conceber um novo sentido diante da marca e dos seus respectivos produtos. A observação de Mozota (2011, pg. 111) esclarece que "Quando se olha um objeto, uma figura mental é construída como resultado de livre associação e projeção. Uma forma pode nos remeter a uma recordação, a um pensamento inconsciente ou a uma crença. A imagem mental pode nos levar de volta a uma construção pessoal e interna que fizemos no passado em interação com o ambiente".

Outro exemplo atual demonstrando o uso de aspectos tradicionais e a preservação de características antigas de um produto é a Manteiga Aviação. A marca de tradição familiar surgida na década de 20 em São Paulo sofreu pouquíssimas alterações na identidade visual. Com 92 anos de história o produto continua sendo comercializado no mesmo modelo de lata, e somente agora ganhou um sistema que dispensa o uso do abridor.

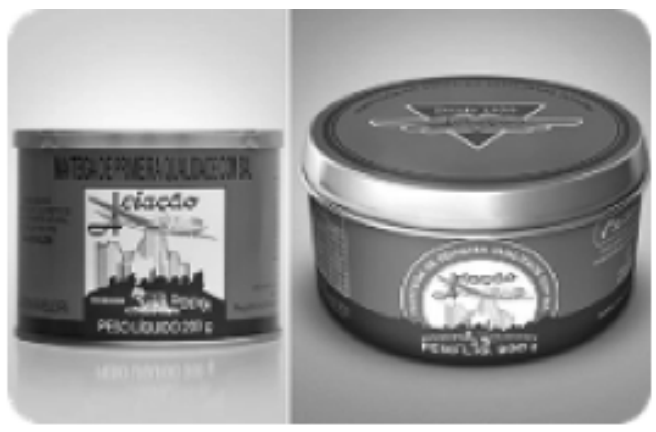

Foto 5 - Detalhe da embalagem antiga da manteiga Aviação e da nova embalagem lançada em janeiro de 2013.

Fonte: www.acil.com.brnoticias-detalhe06022013manteiga-aviacao-muda-de-embalagem 


\section{Estilo Como Negócio. A Tendência Retrô Utilizada Como Recurso Estratégico Nas Práticas da Gestão do Design}

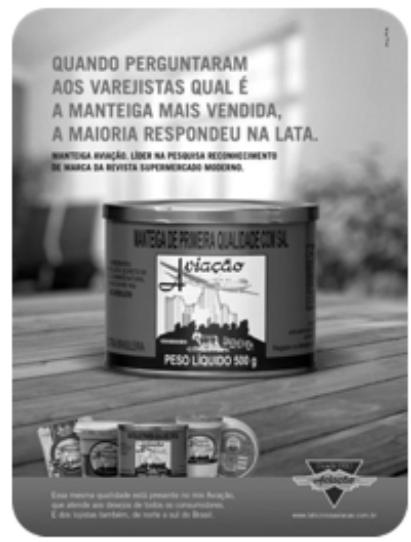

Figura 7 - Anúncio de varejo Manteiga Aviação.

Através de redes sociais e sites próprios que incentivam a proximidade da relação das empresas e consumidores no panorama atual e da interação entre elas, relançar produtos que fizeram sucesso no passado é uma prática recente no mercado. Com intuito de restaurar a imagem da marca, investir na consolidação da identidade e do caráter atemporal dos produtos as empresas lançam edições comemorativas do lançamento de produtos em datas específicas ou ainda apenas atendendo às sugestões dos usuários. Podemos exemplificar esse fenômeno considerando algumas marcas do ramo alimentício que se utilizaram dessa experiência, tais como: Chocolates Lacta, Biscoitos Mabel, Chocolate Lolo Nestlé, Leite condensado Moça, Achocolatado Nescau e Sorvetes Kibon. Produtos que possuem uma essência com valores amplamente desenvolvidos em conexões subjetivas com o usuário, na exaltação dos sentidos como o setor de alimentos são ativos nesse tipo de proposta. 0 passado utilizado como fonte motivadora da percepção da identidade da marca. A memória trabalha como uma reação em cadeia, começando com uma imagem visual dos atributos do produto, o que leva a uma sequencia de elos com o auto conceito do consumidor e com suas percepções dos benefícios do produto. (MOZOTA 2010 pg. 115).
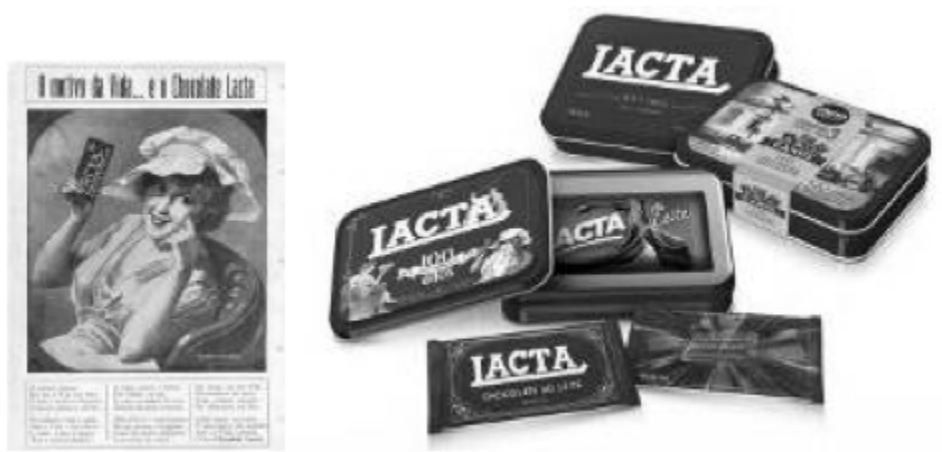

Figura 5 - Antigo anúncio do chocolate lacta e embalagem comemorativa dos 100 anos da marca Fonte (1): www.propagandopropaganda.com.brindex.phpcampanhas-publicitarias 1482--lacta-lanca-latas-retro-que-celebra-100-anos-da-marcaFonte (2): www.almanaque.blog.br 


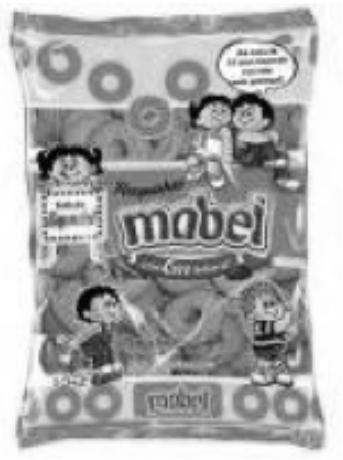

Figura 6 - Embalagem do biscoito Mabel idêntico ao antigo da marca relançado como edição especial Fonte: www.designinnova.blogspot.com.br201107embalagem-mabel-em-estilo-retro.html

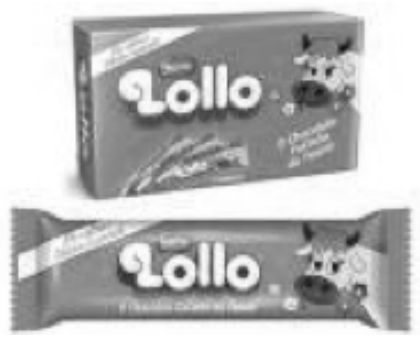

Figura7 - Relançamento do chocolate Lollo, como edição especial, com mesmo design de embalagem e fórmula da versão antiga.

Fonte: www.pratofundo.com3215nestle-lollo-
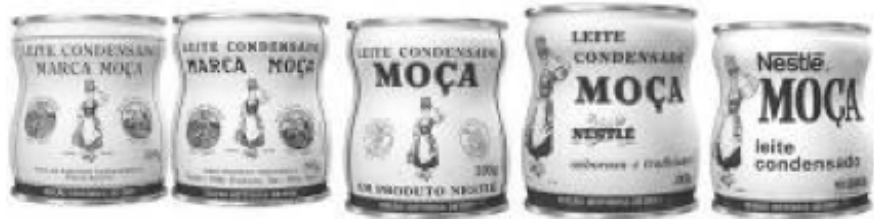

Figura 8 -Leite condensado Moça da nestlé que relançou embalagens de diversas décadas passadas em edições especiais.

Fonte:www.revistacriativa.globo.comRevistaCriativao,,EMI 101707-17769,00-LEITE+CONDENSAD0+DE+COLECIONADOR.html
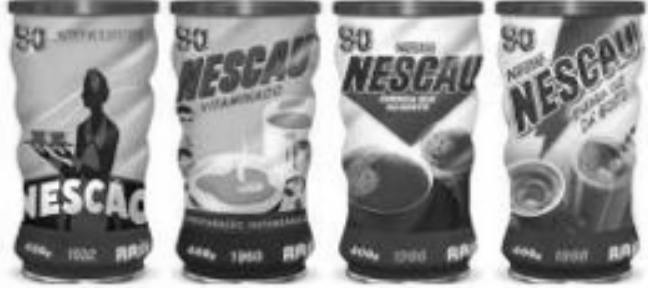

Figura 9 - Achocolatado Nescau relançando embalagens antigas comemorativas.

Fonte: httpdesigninnova.blogspot.com.br201102nestle-lanca-linha-de-embalagens-retro.htmlutm_source=feedburnerđtutm_medium=feedđutm_campaign=Feed+designinnova+(Design+Innova)

0 reconhecimento de uma marca pelo consumidor é um fato construído através do tempo e assume um caráter positivo ao longo dos anos de acordo com os padrões 
da gestão utilizado por uma empresa. A personalidade e os valores da empresa são recebidos aos poucos no decorrer de ações de comunicação e estratégias aplicadas na administração da identidade corporativa. 0 design retrô vem sendo agregado a essas estratégias como contribuição à identidade e a representação simbólica da marca diante dos consumidores. Segundo Mozota (2011, pg. 186):

Essa abordagem cognitiva de estratégia explica a importância da identidade para 0 design estratégico. A identidade da empresa reside em um conjunto de representações, as quais são imagens mentais associadas interna e externamente a uma empresa. As imagens são comunicação recebida que equilibra a identidade presente (a realidade da empresa), a identidade sonhada (a intenção estratégica) e a identidade aceitável (a interação com o ambiente).

Para se obter resultados favoráveis utilizando essa conexão nostálgica a identidade da marca deve estar consolidada no mercado e possuir de fato uma afinidade com os anseios do consumidor final. Na prática dessa relação são necessárias familiaridade e identificação consolidada. A estabilidade do vínculo produto-usuário na relação de consumo é um fator primordial para efetivar a definição por uma estratégia visando os conceitos e formas do design retrô. 0 simbolismo social encontrado na forma é a principal razão para a compra do produto. Um design será considerado importante se projetar um aspecto da autoimagem do consumidor que é importante para ele (MOZOTA, 2011 pg.118). Os elementos nostálgicos são valiosas fontes de significados para os consumidores. Produtos com traços do passado trazem naturalmente lembranças e conexões sentimentais aos usuários. Disso aborda o conceito de design reflexivo conceituado por Norman (2008, pg.37) que está relacionado ao tema, pois "trata dos significados dos produtos, ou de seu uso e aborda as relações de longo prazo, cultura, satisfação em possuir, exibir ou usar e sobre a identidade da pessoa em relação ao produto". A ênfase do mercado nesse estilo vem sendo cada vez mais ampliado por estreitar ainda mais a relação empresa-consumidor. Essa proximidade intencional agrega valor à marca, dá suporte na relação de negócio e propões novas experiências de consumo. Isso elabora o caráter principal do que Belchior (2010, pg.46) conceitua sobre o emocional branding, ou seja, "a marca deixa de ser uma imagem/símbolo que identifica uma empresa, produto ou serviço e passa a estabelecer uma relação emocional com seus clientes."

Além de aspectos emocionais que a utilização estratégica do design retrô traz, há o enfoque comercial. Por parte das empresas seguir essa linha conceitual é sempre uma decisão estratégica, mas pode representar renovação e pode significar em ganhos no preço. 0 resgate de uma linha de produtos já fora do mercado ou mesmo o relançamento de embalagens antigas pode significar novos direcionamentos nos planos de negócios e agregar valor à marca, um das funções práticas do design. 0 design deve identificar os elementos do valor que a diferenciam e conduzir uma visão de longo prazo e relações entre funcionários, consumidores e marca, além de concentrar a mitologia da empresa em torno de histórias que revelem os valores de marca. (MOZOTA 2011, pg. 245).

Um dos critérios mais simples quando se trata da preferência pelo design retrô dos consumidores diante da enorme diversidade dos produtos disponíveis atualmente também faz parte do conceito de identificação: o critério estético. Muitas pessoas por características culturais, valorizações pessoais de estilo tem preferência e revivem intensamente 


\section{Estilo Como Negócio. A Tendência Retrô Utilizada Como Recurso Estratégico Nas Práticas da Gestão do Design}

a relação com a cultura de outros tempos e com clássicos dos mais diversos segmentos. A aposta no design retrô de marcas de produtos eletrônicos como Brastemp e LG se firmaram inicialmente nesse princípio. Lançaram produtos da linha de eletrodomésticos e eletrônicos modernos e tecnológicos com a cara do design de décadas passadas e são sucesso entre os consumidores. 0 que inicialmente era uma aposta tímida e aparentemente com edição limitada se ampliou e continua rendendo em vendas e planos estratégicos de longo prazo.

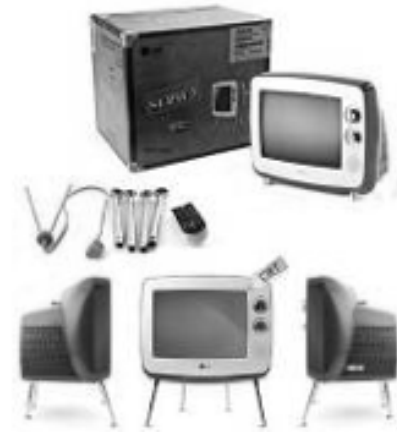

Figura 10 - Televisão Vintage da marca LG.

Fonte: httpdesigninnova.blogspot.com.br201001tv-retro.html

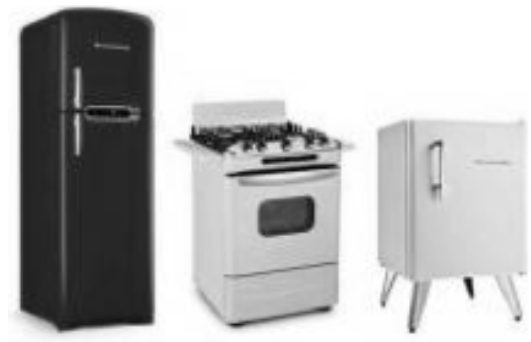

Figura 11 - Linha de produtos da Brastem Retrô.

\section{Conclusão}

0 ambiente cultural no qual estamos situados atualmente é um campo fértil e incitador de novas ideias e tendências para os atuais negócios do mercado. Estamos posicionados em um momento cultural ainda mais propício para a inovação onde possuímos os facilitadores tecnológicos, as aberturas possibilitadas pela comunicação moderna, a internet e o avanço enorme do acesso à informação. Isso tudo gera estruturas motivadoras que formam as novas convenções atuais e ampliam suas dinâmicas, promovendo a disseminação e a determinação de novas relações simbólicas nas mentes dos integrantes desse cenário. Um cenário rico e desenvolvedor de tendências em diversos segmentos, inclusive no mundo do consumo, dos bens materiais e do painel competitivo das empresas e suas marcas.

As tendências comportamentais e associadas ao consumo de mercadorias se traduzem 
como signos dessa cultura, e delineiam um mercado cada vez mais focado no significado dos objetos do que na simples satisfação das necessidades dos consumidores. A contemporaneidade cultural trouxe especificidades muito interessantes nas relações de consumo, nas interações entre as empresas e marcas e disponibiliza um acervo de ideias e novas propostas de negócios. Verifica-se hoje um posicionamento natural das pessoas no mundo moderno ao resgate de suas história e propensas à uma nova interpretação das suas próprias atitudes. Investe-se a partir disso em uma intervenção nos significados dos produtos de consumo e que abre portas para planos estratégicos conscientes dos elementos culturais disponíveis.

A ênfase em ressaltar estímulos através da imaginação, memórias e lembranças agradáveis associadas aos objetos que consumimos deu combustível ao apelo enorme da "onda retrô" inserida no mercado. Esse fenômeno cultural ligado ao potencial criativo das estratégias das empresas valorizam objetos que transportam as vivências das pessoas e fazem com que as expectativas de ter ou reviver lembranças seja materializada. Isso transforma o conceito amplo de "estilo retrô" em uma ferramenta do design e que promove as ações das marcas. A utilização desse recurso na comunicação, na criação e desenvolvimento de novas linhas de produtos é extremamente relevante para a percepção das novas características modernas do mercado.

Aparentemente a utilização do design retrô pelas marcas pode se apresentar como apenas mais um traço particular e momentâneo da nossa cultura de consumo. Observando com um olhar mais crítico e apurado percebemos que diversos fatores importantes na nossa sociedade levaram à construção desse estilo viemos acompanhando. Fatores sociais, culturais e que mais detalhados nos mostram características históricas, antropológicas, econômicas e outros diversos focos temáticos possíveis de validação.

0 simples resgate da usabilidade dos objetos com novas interpretações e variantes já se mostra um amplo material de estudo para acompanhar teorias do design e até de outras disciplinas. Os aspectos estéticos antigos, a comunicação, o estilismo do passado retornando como foco principal nas estratégias das empresas demonstra o quanto termos como inovação e criatividade ainda podem surpreender nos negócios e o quanto 0 design tem se tornado fundamental. As motivações das empresas para investir no apelo retrô são variadas, assim como a preferência dos consumidores por esse estilo. Desde o simples encantamento com o fator estético de um produto até a escolha por diferenciação diante da gigantesca oferta de produtos disponíveis, o design retrô ganha espaço no mercado e não passa despercebido por setores gerenciais e estratégicos das empresas.

Colocar em evidência de maneira original aspectos do passado e resgatar formas e outros atributos clássicos de forma criativa é um desafio. Um desafio que tem sido levado em consideração e vem fazendo parte das estratégias de marcas, através de atitudes práticas em planejamento de gestão. Identificação, diferenciação e até posicionamento principal de identidade de uma empresa diante dos consumidores são alguns dos pontos chaves nesses planos. Muito mais do que o usual foco na ênfase da tradição e história de uma empresa, quase uma regra na comunicação institucional, o design retrô é apontado como diferencial emblemático nos processos estratégicos. Isso tem sido concretizado através de ações de relançamentos visando aproximação com o consumidor 


\section{Estilo Como Negócio. A Tendência Retrô Utilizada Como Recurso Estratégico Nas Práticas da Gestão do Design}

e conquista de novos clientes. Tem ressaltado a contribuição histórica do design gráfico com o destaque e enaltecimento às embalagens antigas, aos traços estilísticos clássicos e consagrados da cultura popular, assim como vem incitando as particularidades específicas de determinadas épocas marcantes para o consumidor e para a cultura em geral.

Na prática gerencial de setores de comunicação e marketing, o design retrô como estratégia de negócio mostra que todas as suas possibilidades podem se traduzir em lucros, renovação e até em uma total transformação de atitude diante do mercado. Introduzindo ainda mais os conceitos do design dentro das empresas, o estilo agrega ainda mais potencial aos métodos de gestão. Abrem-se mais caminhos para atuação do design como fator primordial nos processos de planejamento e indo muito além do uso estético e funcional. Vislumbra-se ainda a importância do papel do designer nas empresas e atuando de forma mais eficaz na gestão do design e todas as suas relações. Isso tudo coloca em evidência o compromisso cultural e social que o designer pode desempenhar através da visualização estratégica empresarial, da sua competência em identificar as informações do mercado e aptidão ao inovar nos processos de gerenciamento. 


\section{(0) Estilo Como Negócio. A Tendência Retrô Utilizada Como Recurso Estratégico Nas Práticas da Gestão do Design}

\section{Referências Bibliográficas}

$>$ MOZOTA, Brigitte, Borja de. Gestão do Design: Usando o design para construir valor de marca e inovação corporativa. Porto Alegre: Bookman , 2011.

> BURDEK, Bernhard E. Design: História, teoria e prática do design de produtos. 2 ed. São Paulo: Blucher, 2010.

$>$ NORMAN, Donald A. Design Emocional:porque adoramos (ou detestamos) os objetos do dia-a-dia. Rio de Janeiro: Rocco, 2008.

> FIELL, Charlotte e Peter. Design do século XX. Taschen, 2005.

> SCOLARI, Sérgio Henrique, Prado. Um modelo de círculos de referências de emoções em produtos. Disponivel em: 〈http://www4.faac.unesp.br/posgraduacao/design/dissertacoes/pdf/sergio_scolari.pdf>. Acesso em: 20/10/2012

$>$ MELO, Felipe Domingues Machado. Design e cultura em produtos globais: as semiótoca como ponto de convergência. Disponível em: 〈http://www.livrosgratis.com.br/arquivos_ livros/cp073087.pdf > Acesso em: 20/10/2012

> OLIVEIRA, Vânia, Brasz de. 0 consumo retrô: valorizando o passado, evocando emoções. Disponível em: 〈http://www2.metodista.br/unesco/1_Ecom\%202012/GT1/36.0\%20 consumo\%20retr\%C3\%B4\%20hoje_Vania\%20Nogueira.pdf>. Acesso em: 20/10/2012

$>$ ROHENKOHL, Raquel Andressa Stefeni. Design Retrô: um desafio da contemporaneidade em reconhecimento ao passado. Disponivel em: < http://editora.unoesc.edu.br/index. php/acsa/article/view/1085/pdf_229>. Acesso em: 20/10/2012

$>$ HERNANDEZ, Júlia Nogueira. A nostalgia enquanto tendência de comportamento entre os jovens da geração Y. Disponível em: 〈http://www.lume.ufrgs.br/bitstream/handle/10183/37563/000822583.pdf?sequence $=1>$. Acesso em: 20/10/2012

> BELCHIOR, Camilo de Lelis. Reciclando os sentidos: 0 papel do design na ressignificação dos objetos. Disponível em: <http://www.ppgd.uemg.br/wp-content/uploads/2012/08/ Camilo-de-Lelis-Belchior.pdf〉. Acesso em: 20/10/2012

> INFOPEDIA. Enciclopédia e Dicionários Porto Editora: Cultura Material. Disponível em: 〈http://www.infopedia.pt/\$cultura-material〉. Acesso em: 20/10/2012 
Caroline Basso, Aluna do curso de especialização em Gestão de Design da UFSC caroline.basso@hotmail.com

Richard Perassi Luiz de Souza, Doutor em Comunicação e Semiótica (PUC/SP, 2001). Atua no curso de graduação em Design e nos programas de pós-graduação em Design e Expressão Gráfica (PóS-DESIGN/UFSC) e pós-graduação em Engenharia e Gestão do Conhecimento (EGC/UFSC).

richard.perassi@uol.com.br

Sharlene Melanie Martins de Araújo, Cursando o Mestrado no Programa de pós-graduação em Design e Expressão Gráfica (Pós-Design/UFSC)

sharlene.melanie@gmail.com 